\title{
Psychological and pedagogical features of the relationship between subjective control and anxiety of students in the practice of the educational process of the university
}

\author{
Laura Kagermazova ${ }^{1,},{ }^{*}$ Zarema Masaeva $^{2}$, Ahmed Azhiev $^{2}$ and Tsiala Kalmanova ${ }^{2}$ \\ ${ }^{1}$ Chechen State University, Grozny, 364093, Russia \\ ${ }^{2}$ Chechen State Pedagogical University, Grozny, 364024, Russia
}

\begin{abstract}
The article examines the peculiarities of the relationship between subjective control and anxiety of students of humanitarian and medical specialties of the university, the development of self-regulation and its connection with self-knowledge of students. The purpose of the research is to study the relationship of subjective control and anxiety of participants in the educational process, the relationship of personal characteristics that affect anxiety in students of various specialties. An understanding of the terms anxiety and disquiet in various psychological concepts shown in article. The idea of self-knowledge in this study realized by various specialties of the university in humanitarian and medical. The manifestation of anxiety, self-regulatory mechanisms in the educational process, taking into account the psychological characteristics of students of humanitarian and medical specialties, is considered. Factors of influence on the student's anxiety are determined: strong-willed characteristics, self-knowledge, development of self-regulation, coping strategy. The following research methods were used in the empirical part: the technique "Spielberger-Khanin Scale of Reactive (Situational) and Personal Anxiety," the PlutchikKellerman-Conte personal questionnaire "Lifestyle Index," the ZverkovAdman test questionnaire "Volitional self-diagnosis" as well as methods of mathematical statistics for processing the results. An empirical study conducted to identify the connection of anxiety, strong-willed characteristics with the abuse of psychological protection mechanisms for students of humanitarian and medical specialties of the university.
\end{abstract}

\section{Introduction}

Reformation of professional education system in Russia makes new demands on the organization of the learning process in the basic educational programs of higher education. This usually takes into account two components of the educational process: professional and personal. The professional component correlated with the requirements of the Federal state educational standard (in this area/specialty), the personal component is those life values and value orientations that the student has and that can become the Foundation for the success of

\footnotetext{
* Corresponding author: laura07@yandex.ru
} 
professional training. This allows you to combine theory with practice, to adapt the competencies formed by students at the University to the conditions of a specific activity as much as possible. The relevance of the topic under study is the need to understand the phenomenon of anxiety, its functions in human life. Consideration of the possibilities of controlling anxiety will help to minimize its non-constructive impact on the educational process. Scientists considered the problem of anxiety: Granovskaya R. M., T. V. Tulupyeva, A. M. Parishioners, Shatilova, T. G. [1-4] Among foreign researchers, you can find such famous names as Z. Freud, K. Horney, and C. Spielberger. They tried to sort out how psychological defense mechanisms formed and how they help in the fight against anxiety. According to S. V. Baranova, anxiety can suppress volitional characteristics [2-4]. And they, in turn, influence the choice of defensive behavior. Therefore, it is necessary to form selfregulation, since it affects all types of personal activity [2-4]. It is possible to overcome these negative phenomena and at the same time provide a high level of professional training by creating certain psychological and pedagogical conditions for ensuring the success of students ' education. The task of forming self-regulation and self-control is fixed in the CC6 of the Federal state educational standard in 3++ FOR all areas of bachelor's degree (selforganization and self-development), which emphasizes the relevance of this study. The article shows that there is a connection between self-knowledge and anxiety control, therefore, students of the humanities specialty in the learning process characterized by a decrease in anxiety and a decrease in the use of immature mechanisms of psychological defense with a slight increase in volitional characteristics. For representatives of the medical specialty, a decrease in anxiety and the use of immature mechanisms of psychological defense will also be characteristic, but due to an active increase in volitional characteristics; and volitional characteristics have an inverse correlation with the mechanisms of psychological defense and anxiety, regardless of specialty.

\section{Materials and methods}

In the empirical part, the following research methods were used, the Spielberger-Khanin Scale of Reactive (Situational) and Personal Anxiety, the Plutchik-Kellerman-Conte personality questionnaire "Lifestyle Index", the Zverkov-Adman test questionnaire "Research of volitional self-regulation", as well as methods mathematical statistics for processing the results obtained. Statistical processing of the data carried out using the Shapiro-Wilk normal distribution test and Pearson and Spearman correlation coefficients [3]. The study was conducted among first and fourth year students of the humanities (psychological) and medical specialties.

\section{Results}

Based on the results of the correlation analysis carried out within the framework of the study, we can conclude that there is a significant correlation between a high level of personal anxiety and abuse of immature mechanisms of psychological defense. According to the results of a study of the level of anxiety in 20 subjects of the humanitarian direction (40\% of the total number of this group), personal anxiety is in the zone of high rates; among students of a medical specialty, the number of highly anxious subjects is 28 (49\% of the total number of students in this specialty). The average indicators of the general tension of defenses in the humanities of the first year were 50 , in the representatives of the medical specialty - 53. To identify the connection between personal anxiety and abuse of the mechanisms of psychological defense, a correlation analysis carried out. For features with a normal distribution was used the parametric Pearson correlation test. To calculate the correlation of 
features with a distribution other than normal was used Spearman's nonparametric rank correlation coefficient.

In the first courses of the humanitarian direction, a significant negative correlation was revealed between indicators of will and abuse of such an immature mechanism of psychological defense as regression $(\mathrm{r}=-0.487 ; \mathrm{p}=0.016)$. Also, a weakly significant negative correlation of will with compensation $(\mathrm{r}=-0.431 ; \mathrm{p}=-0.036)$ and projection $(\mathrm{r}=$ $0.440 ; p=0.031)$ was revealed. The subjects with high volitional indices use less such mechanisms of psychological defense as substitution, regression, compensation and projection.

In addition to connections with volitional characteristics, psychological defense mechanisms have connections with personal anxiety. At a high level of significance, personal anxiety correlates with regression $(r=0.692 ; p=0.000)$, compensation $(r=0.539 ; p=0.007)$, substitution $(r=0.552 ; p=0.005)$, and the overall strength of defenses $(r=0.592 ; p=0.002)$. The higher the personal anxiety, the more actively the first-year students of the humanities resort to regression, compensation and substitution. However, the more they have a general defense intensity.

In the fourth year of the humanitarian profile, there is a correlation between will and intellectualization $(r=0.476 ; p=0.014)$, regression $(-0.483 ; p=0.012)$ and denial $(r=0.502$; $\mathrm{p}=0.009)$. Inverse correlation in regression - therefore, the higher volitional indicators, the less regression is used, and positive correlations in intellectualization and denial - the higher the will, the more often these defense mechanisms are used.

If we look at the correlation analysis of persistence and mechanisms of psychological defense, then of all the mechanisms of psychological defense, correlation is observed only with denial $(r=0.507 ; p=0.008)$, which suggests that the more persistent a student is, the more he is inclined to deny the uncomfortable, causing anxiety information.

Self-control tests revealed its correlation with regression $(r=-0.489 ; p=0.011)$ and intellectualization $(\mathrm{r}=0.456 ; \mathrm{p}=019)$. The inverse correlation of self-control with regression means that the higher the self-control, the less the respondent applies regression. Personal anxiety correlates with denial $(r=-0.644 ; p=0.000)$ and regression $(r=0.464 ; p=0.017)$. Direct correlation with regression - higher anxiety, more regression is used. An inverse correlation with denial shows that the higher the personal anxiety, the less often a person resorts to denial. If we talk about the first year of medical specialty, then there were no significant correlations with volitional characteristics, but there is a weakly significant correlation between personal anxiety and regression $(\mathrm{r}=0.372, \mathrm{p}=0.030)$. The higher the level of a student's personal anxiety, the more he resorts to such a mechanism of psychological defense as regression. Fourth year medical students have insignificant correlations of will with regression $(\mathrm{r}=-0.467 ; \mathrm{p}=0.025)$ and projection $(\mathrm{r}=-0.492 ; \mathrm{p}=$ $0.017)$ and a high significance of correlation between will and denial $(r=0.589 ; p=0.003)$. If the will is high, then regression is used less. Moreover, negative is a direct correlation - the higher the will, the more often this mechanism is used. Self-control has a weak direct correlation with denial $(r=0.422 ; p=0.045)$ and intellectualization $(r=0.457 ; p=0.029)$, which means that the higher the level of self-control, the more a person uses intellectualization and denial. In addition, self-control is inversely correlated with regression $(\mathrm{r}=-0.525 ; \mathrm{p}=0.010)$, projection $(\mathrm{r}=-0.601 ; \mathrm{p}=0.002)$, and displacement $(\mathrm{r}=-0.637 ; \mathrm{p}=$ 0.001). Less self-control means more regression, projection and substitution indicators. With personal anxiety according to Pearson, such relationships were found: with denial $(r=-0.434$; $\mathrm{p}=0.039)$, with regression $(\mathrm{r}=0.526 ; \mathrm{p}=0.010)$, with substitution $(\mathrm{r}=0.578 ; \mathrm{p}=0.004)$, with intellectualization $(\mathrm{r}=-0.560 ; \mathrm{p}=0.005)$, with a projection $(\mathrm{r}=0.454 ; \mathrm{p}=0.030)$ and with a total protection strength $(\mathrm{r}=0.463 ; \mathrm{p}=0.026)$. Personal anxiety correlates with regression, with substitution, with projection, and with $\mathrm{OHZ}$ - the level of one value is higher, respectively, the level of the second is higher. Anxiety is inversely correlated with denial and 
intellectualization, therefore, the higher the level of anxiety, the less denial and intellectualization are used.

The arithmetic mean of the total defense tension in the fourth year of both directions is 48. Among highly anxious students of the humanities, such a mechanism of psychological defense as denial is used, 11 people (55\%), 8 people (40\%) - suppression, 20 people $(100 \%)$ - regression. Among medical students with a high level of personal anxiety, these values were distributed as follows: denial - 17 people (61\%), suppression - 16 people $(57 \%)$, regression - 19 people (68\%).

Students with a high indicator of personal anxiety choose such mechanisms of psychological defense as denial and regression, which confirms the hypothesis put forward about the presence of a connection between these signs, allows us to talk about the need for psychological and pedagogical support and taking specific measures in order to make a person's activity and communication more effective. In addition to searching for correlations, an analysis and comparison of the arithmetic means of the use of immature mechanisms of psychological defense by first and fourth year students of both specialties was carried out. The arithmetic mean of denial, suppression, regression in the first courses of the humanities is 57,44 , and 52 , respectively. By the fourth year, these values change slightly negation - 58, suppression - 41, regression - 50. In medical students, the difference between the first and fourth year is more noticeable. If in the first courses denial - 52, suppression - 49, and regression - 56, then in the fourth course denial increases to 58, suppression decreases to 44, regression drops sharply to 39. A sharp decrease in regression and, at the same time, an increase in denial indicates the typical behavior of a young a person when there is a desire for independence, but an unwillingness to take responsibility for their actions. The volitional indicators change as follows - in the first courses of both profiles, will - 12, persistence and self-control - 7. In the fourth year of humanitarian training areas, will - 14, persistence - 10 and self-control remains at the same level. Medical students in their fourth year have a will of 15 , perseverance -9 , self-control - 8 .

The study allows outlining the ways and means of achieving individual psychological security and the ability to effective social and psychological adaptation.

Thus, it can be concluded that there are differences in the regulation of high levels of anxiety between the humanitarian and medical specialties. If initially, among the first courses, the arithmetic mean of the general defense intensity for humanities is 50, and for representatives of the medical specialty - 53. By the fourth year, the total defense strength in both directions decreases to 48. In humanitarian directions, a smoother change in use is observed over four years immature mechanisms of psychological defense. At this time, among students of the medical specialty, noticeable differences in the average values of immature psychological defense mechanisms can be observed, especially in regression (from 56 to 39). This could mean that medical students are less adaptive, students are more selfcentered and self-centered, and those that are beyond their capacity they prefer to ignore.

Based on the analysis of the literature and empirical research, a correctional program will be formed for psychological and pedagogical accounting and control of the level of anxiety, improving the skills of using methods of reducing anxiety, preventing the individual from resorting to the use of immature mechanisms of psychological defense.

\section{Discussion}

On the grounds of literary sources was suggested that the level of personal anxiety determines which mechanisms of psychological defense a person chooses. A study was conducted, the purpose of which was to check the presence of a connection between a high level of personal anxiety and subjective control - the choice of psychological defense mechanisms. To achieve the formulated goal, the following tasks were set and consistently solved: the understanding 
of anxiety and disquiet in various psychological concepts was revealed; the features of the concept of emotions by R. Plutchik and the possibility of emotional self-regulation are considered; factors of influence on uncontrolled anxiety - volitional characteristics, selfknowledge, development of self-regulation, mechanisms of psychological defense, coping strategies; the possibilities and limitations of anxiety management in the educational process have been studied, taking into account the psychological characteristics of first and fourth year students of the humanitarian and medical specialties; studied methods of researching anxiety and various aspects of protection against anxiety; an empirical study was carried out, involving the identification of the connection between the training profile, anxiety, volitional characteristics with the abuse of psychological defense mechanisms; a correctional program for psychological and pedagogical accounting and control of the level of anxiety in the educational process and in everyday life will be formed.

The theoretical chapter analyzed definitions of anxiety and ways of working and coping with it. Anxiety is an individual psychological feature of a person, which manifests itself in anxiety in situations of real or imaginary threat. Z. Freud defined anxiety as something deep and irrational, as an objectless fear. Anxiety, worry, fear are often present in our mental life. They can vary in intensity, duration, structure; can perform various functions, both adaptive and disorganizing mental activity [5-10]. For example, mild anxiety plays an adaptive role in helping a person to mobilize reserve capacity in difficult life circumstances. However, panic, horror (an intense degree of anxiety) block the effective functioning of mental functions and have a disorganizing effect on the psychophysiological functions of a person. A person seized with horror loses the ability to adequately assess what is happening and make the appropriate decisions. Obviously, such anxiety requires overcoming, since it prevents a person from functioning normally. In order to cope with this state, one should act oversituationally (for example, setting a goal is a manifestation of will), transforming the state into a certain behavior, and using psychological defenses. The mechanisms of psychological defense allow a person to reduce the anxiety caused by a stressful situation; they automatically correct the subjective perception of the world to maintain a person's calmness [10-12]. R. Plutchik, who studied the mechanisms of psychological defense, identified eight mechanisms - denial, suppression, regression, compensation, substitution, projection, intellectualization, rationalization. He also divided the mechanisms according to "maturity" : "immature" distort reality as much as possible, not helping to eliminate the stress factor (denial, suppression, regression), "more mature" mechanisms - reduce stress, and the "most mature" ones approach the mechanisms of coping with anxiety and stress in their ability to compensate for stress.

\section{Conclusions}

This study allows us to draw conclusions:

1. The presence of a connection between the profiles of training, anxiety, volitional characteristics with the abuse of psychological defense mechanisms.

2. A connection was revealed between self-knowledge and anxiety control, therefore, for students of the humanities specialty in the learning process will be characterized by a decrease in anxiety and a decrease in the abuse of immature psychological defense mechanisms with a slight increase in volitional characteristics, for representatives of the medical specialty, a decrease in anxiety and abuse of immature psychological defense mechanisms will also will be characteristic, but due to an active increase in volitional characteristics.

3. Volitional characteristics are inversely correlated with regression and directly correlated with denial, regardless of the profile. The abuse of the mechanisms of psychological defense, mainly of an immature type, will dominate in the first years, and a more significant decrease will be typical for students of humanitarian specialties. First-year 
students of all educational profiles characterized by the abuse of immature mechanisms of psychological defense in people with an increased level of anxiety and the absence of welldeveloped coping strategies. In freshmen, personal anxiety will be higher, and its decrease will be more significant in students of the medical specialty.

4. In order to make educational activities and communication of a person more effective, it is necessary to take into account the difference in the skill of self-knowledge among students of various specialties of the university.

5. Studentship is a difficult period in a person's life. During this time, the individual formed not only physically, but also mentally, as a person. Since this age period has a huge impact on the personal and professional development of an individual, anxiety should not interfere with the successful passage of this stage [12-15]. To solve the problem of high anxiety and help students in overcoming it, psychological and pedagogical support of the participants in the educational process is necessary.

\section{References}

1. G.V. Vanakova, Vector of Science of Togliatti State University. Series: Pedagogy. Psychology 3(10), 36-40 (2012) DOI: 10.18323

2. T.V. Ledovskaya, D.A. Biryukova, Yaroslavl Pedagogical Bulletin 2, 211-215 (2017) DOI: 10.20323

3. O.I. Mukhrygina, Omsk Scientific Bulletin 10(49), 153-156 (2006) DOI: 10.25206

4. E.A. Deryabina, Natural and humanitarian research 1(1), 130-134 (2013) Doi: 10.24411

5. N.A. Kiselevskaya, Bulletin of the Irkutsk State University. Series: Psychology 8, 34-38 (2014) DOI: 10.26516 / 2304-1226

6. T.M. Maslova, Vector of Science of Togliatti State University 4(30), 168-171 (2014) DOI: 10.18323

7. A.A. Nikitin, N.A. Petrovanova, Bulletin of Perm University. Philosophy. Psychology. Sociology 3(19), 75-82 (2014) DOI: 10.17072 / 2078-7898

8. E.E. Bocharova, O.S. Protasevich, Izvestiya Saratov University. New series. Series: Acmeology of Education. Developmental psychology 2, 177-183 (2013) DOI: 10.18500 / 2304-9790

9. A.I. Mednikova, Austrian Journal of Humanities and Social Sciences 1-2, 290-296 (2014) Doi: 10.29013

10. A.Kh. Kodzokov, L.Ts. Kagermazova, Historical and socio-educational thought 6(5), 151-154 (2014)

11. L.Ts. Kagermazova, Kazan Pedagogical Journal 6, 49 (2014) DOI: 10.34772

12. Z.V. Masaeva, L.Ts. Kagermazova, I.V. Abakumova, Bulletin of the Kostroma State University 21(2), 80 (2015) DOI: 10.34216 / 1998-0817

13. L.Ts. Kagermazova, I.V. Abakumova, V.F. Boguslavskaya, Russian psychological journal 10(5), 39-55 (2013) Doi: 10.21702

14. S.D. Nedelcut, N. Nedelcut, D.C. Leucuta, D.L. Dumitrascu, 4th International Multidisciplinary Scientific Conference On Social Sciences And Arts Sgem, Conference proceedings (Sofia, 2017) 